\title{
Estándares conceptuales y cargas procesales en el litigio antidiscriminación. Análisis crítico de la jurisprudencia sobre Ley Zamudio entre 2012 y 2015
}

\author{
Fernando Muñoz León*
}

\begin{abstract}
RESUMEN
El presente artículo ofrece un análisis crítico del conjunto de sentencias de primera instancia dictadas por tribunales nacionales en conocimiento de la acción establecida en el Título II de la Ley de Medidas contra la Discriminación, popularmente conocida como Ley Zamudio. El artículo concentra su atención en la conceptualización que dicha jurisprudencia bace de la discriminación mediante la identificación de elementos que deben concurrir para que ella esté presente, y en la forma en que la misma aborda la carga de probar y justificar la conducta sometida a escrutinio. El artículo concluye afirmando que la revisión crítica, al tiempo que confirma las críticas al texto de la ley ofrecidas por diversos académicos, sugiere también la necesidad de complementar nuestra cultura jurídica mediante la reflexión teórica acerca del fenómeno discriminatorio.
\end{abstract}

Derecho antidiscriminación - estándar conceptual - carga probatoria - reparación

\section{Conceptual standards and procedural burdens in antidiscrimination litigation. Critical analysis of case law on the Zamudio Act between 2012 and 2015}

ABSTRACT

This article offers a critical analysis of the decisions issued by Chilean lower courts with respect to the remedy created by Title II of the Law of Measures Against Discrimination, also known as the Zamudio Act. The article concentrates its attention in the concept of discrimination that the case law offers in the form of elements that constitute it, and in its understanding of how to discharge the burden of proof and justification involved in the lawsuit. The article concludes arguing that this critical appraisal, at the same time that confirms the criticisms to the letter of the law articulated by several scholars, also suggests the need to complement our legal culture through a careful reflection on the phenomenon of discrimination.

Antidiscrimination law - conceptual standard - burden of proof - burden of justification

* Licenciado en Ciencias Jurídicas y Sociales, Pontificia Universidad Católica de Chile. Abogado. Doctor en Derecho, Universidad de Yale; Profesor Asistente, Universidad Austral de Chile. Este artículo forma parte del Proyecto Fondecyt de Iniciación en la Investigación N N 11121191, titulado "El concepto de 'grupos desaventajados' como complemento a la dogmática constitucional chilena sobre igualdad”, del que el autor es investigador responsable. El autor agradece los comentarios de los participantes en el Seminario Austral de Derecho, llevado a cabo en la Universidad Austral de Chile el 26 de junio de 2015; del Coloquio de Derecho Constitucional realizado en la Universidad Diego Portales el 13 de julio de 2015; y de los árbitros anónimos que revisaron este texto.

Artículo recibido el 15 de marzo de 2015 y aceptado para su publicación el 28 de agosto de 2015. 


\section{INTRODUCCIÓN}

$\mathrm{L}$ a acción de no discriminación contenida en la Ley Zamudio se sitúa en una ambigua e insuficientemente teorizada posición respecto del principio general de igualdad y no discriminación arbitraria proclamado en el artículo $19 \mathrm{~N}^{\mathrm{o}} 2$ de la Constitución Política de la República, de la acción de protección contemplada en el artículo 20 del mismo texto normativo, y de la jurisprudencia emanada de nuestros tribunales de justicia respecto de dicha acción. ¿Entraña dicha ley una concreción de dicho principio respecto de algún fenómeno social específico? ¿Consiste sencillamente en una innovación procesal destinada a superar las críticas dirigidas contra la acción de protección?

Además, es importante juzgar esta ley en particular a la luz de las expectativas que la sociedad civil organizada y la opinión pública mantienen respecto de dicha obra legislativa. Creo no equivocarme si afirmo que, para las agrupaciones de la sociedad civil y los académicos que participaron activamente en la preparación de este proyecto de ley, y que luego lo apoyaron a lo largo de su tramitación, la razón de ser de dicho proyecto consistía en la percepción que dichos sectores tenían respecto de la jurisprudencia de protección en materia de igualdad, la que consideraban que había demostrado no tener una orientación garantista o de protección de las víctimas de discriminación. Esta crítica a la jurisprudencia de protección relativas a igualdad, que podríamos calificar como social, es distinta de aquella crítica conceptual formulada por diversos académicos consistente en apuntar a su carencia de criterios delimitadores que permitan distinguir las diferenciaciones que vulneran la garantía de igualdad de aquellas que no lo hacen. Como le reprochara Atria a la Corte Suprema, "la igualdad se opone a discriminaciones que a ella le parecen obviamente privadas de razón, pero no ha hecho público cómo (demonios) esto se puede saber de antemano"1.

Al momento de ser publicado este artículo se habrá ya verificado el tercer aniversario de la entrada en vigencia de la Ley 20.609, de Medidas contra la Discriminación (en adelante, Ley Zamudio). Este hito es una buena oportunidad para evaluar los resultados jurisprudenciales que ese cuerpo legislativo ha tenido hasta el momento; particularmente, para evaluar si la jurisprudencia emanada de nuestros tribunales ha logrado contribuir de manera efectiva al combate contra la discriminación ${ }^{2}$. El presente trabajo ofrece al lector una selección de algunas de las consideraciones y argumentos ofrecidos por las 42 sentencias de primera instancia dictadas desde la entrada en vigencia de la ley, y hasta el cierre de la edición de este artículo, recaídas en procedimientos tramitados de

\footnotetext{
${ }^{1}$ Atria, F., Los Peligros de la Constitución, Universidad Diego Portales, Santiago, 1997, p. 89.

${ }^{2}$ En un anterior trabajo he concluido que el resultado es bastante desalentador tanto cuantitativamente, debido al bajo número de sentencias de primera instancia que acogen la pretensión del demandante, como cualitativamente, considerando el tipo de pretensiones que recibieron protección y aquellas que no. Véase Muñoz, F., "La Ley Zamudio en acción: sentencias de primera instancia sobre acción antidiscriminación emitidas entre diciembre de 2012 y marzo de 2015", en Anuario de Derecho Público (Universidad Diego Portales), vol. 6, 2015.
} 
acuerdo con la acción de no discriminación contemplada en el Título II de dicha ley. Antes de proceder al análisis en cuestión, explicitaré las premisas teóricas que guían mi análisis, enmarcadas en un esfuerzo de mayor alcance por elaborar una teoría jurídica de la discriminación. La exposición deberá ser brevísima, no solo porque su adecuada elaboración requiere de un esfuerzo que excede este espacio ${ }^{3}$, sino también porque ella es hecha al costo de restar espacio al análisis de la jurisprudencia antidiscriminación, que constituye el objeto específico de este trabajo. Así y todo, se hace necesario esta ajustadísima exposición a fin de que el lector comprenda en virtud de qué consideraciones he realizado la selección y formulo las críticas que aquí le ofrezco.

Cotidianamente, una parte significativa de la población que vive en países de cultura y estructura social occidental experimenta diversas formas de discriminación en razón de su pertenencia a alguna categoría estructuralmente desaventajada o, como diré aquí de manera más breve, grupo desaventajado. El contexto del fenómeno en cuestión lo ofrece un conjunto de procesos sociológicos de proyección histórica y alcance global que, sin perjuicio de su gran complejidad, pueden ser resumidos sucintamente. La conquista y colonización europea de las más diversas poblaciones humanas a partir del siglo XVI permitieron la expansión por todo el globo terráqueo de la estructura social patriarcal y el sistema de producción capitalista característicos de la metrópoli, así como de los sistemas de creencias y las instituciones jurídicas encargadas de dar justificación y operatividad a aquellas formas de organización social. Debido a las características jerárquicas de la estructura social y del sistema de producción así expandidos, así como del proceso mismo de sometimiento de los demás pueblos, las sociedades occidentales u occidentalizadas mantuvieron o desarrollaron patrones estables de distribución desigual del bienestar, del estatus, y de la posibilidad de tomar decisiones; es decir, de desigualdad material, simbólica y política. Sin embargo, los compromisos ideológicos de la civilización occidental con cierto tipo de libertad y con cierto tipo de igualdad ha también provisto de recursos discursivos e institucionales para quienes, a lo largo de los siglos, han combatido la opresión y la subordinación. Pese a tales esfuerzos, los patrones de desigual distribución material, simbólica y política en cuestión evidencian una gran resiliencia. Ellos adquieren su estabilidad gracias al uso de ciertos marcadores o atributos, denominados como adscriptivos por la literatura especializada, y que son de relativamente fácil identificación, ya sea porque están inscritos en la corporeidad del sujeto (como ocurre con los caracteres sexuales secundarios, el color de piel y cabellos, o la existencia de capacidades físicas disminuidas), ya sea porque el sujeto mismo suele revelarlos, incluso involuntariamente, en un conjunto de comportamientos que pertenecen al ámbito de la presentación de la persona en la vida cotidiana (cosa que puede ocurrir con la orientación sexual, la identidad de género, o la identidad de clase). La mentalidad socialmente prevaleciente construye díadas, contrastes u oposiciones en torno a estos atributos adscriptivos, estableciendo asimetrías entre quienes detentan atributos adscriptivos

${ }^{3}$ El autor está actualmente trabajando en un texto que abordará con la suficiente detención esta tarea, y que llevará por nombre Derecho Antidiscriminación. El tratamiento jurídico de la desaventaja adscriptiva. 
socialmente valorados y quienes detentan atributos adscriptivos socialmente minusvalorados o disvalorados. En ambos casos ello se expresa en la construcción de estereotipos que cumplen funciones descriptivas, evaluativas y prescriptivas; es decir, proposiciones que atribuyen características a los sujetos en cuestión, que evalúan dichas características, y que prescriben cursos de acción frente a tales sujetos y sus características. Un estereotipo ventajante lleva a quien lo suscribe a dar un tratamiento favorable a quien detenta atributos adscriptivos socialmente valorados; un estereotipo desaventajante lleva a quien lo suscribe a dar, inversamente, un tratamiento desfavorable a quien exhibe atributos adscriptivos socialmente minusvalorados o disvalorados. Las sucesivas interacciones influenciadas por estereotipos ventajantes o desaventajantes a las que cada sujeto se va enfrentando cotidianamente en la vida inciden en su desarrollo humano, ya que dichas interacciones proveen o deniegan oportunidades para el desarrollo de capacidades y para el goce efectivo de bienes sociales primarios. El ciclo de la desventaja adscriptiva consiste en un caso paradigmático de profecía autocumplida: el entorno le entrega a cada individuo un conjunto de estímulos distintos según los estereotipos dentro de los cuales el individuo esté catalogado; en consecuencia, el individuo desarrolla atributos que confirman el estereotipo. Incluso más, el propio individuo suele internalizar el estereotipo, reconociendo "libre" y "espontáneamente" en sí mismo las virtudes, defectos, o cualidades que la mentalidad socialmente prevaleciente le atribuye a personas como él.

La desventaja adscriptiva, sin embargo, no sería fuente de conflictos sociales si no fuese porque los compromisos ideológicos de la cultura occidental con la libertad y la igualdad han llevado al surgimiento y proliferación de expectativas, por parte de los individuos pertenecientes a grupos desaventajados, no amparadas por los estereotipos respectivos. El conflicto social que se desarrolla así toma la forma de un enfrentamiento entre individuos que pujan por apartarse de la normatividad contenida en el estereotipo, e individuos que la obedecen y buscan imponérsela a sus destinatarios. En los primeros momentos de tal enfrentamiento, la mentalidad socialmente prevaleciente y las instituciones suelen explícitamente respaldar la imposición del estereotipo de una manera represiva. A medida que el grupo desaventajado en cuestión va logrando conquistas, las mentalidades y las instituciones abandonan su carácter abiertamente represivo, pero suelen adoptar actitudes "neutrales" y "tolerantes" que, en nombre de una conceptualización de la libertad como libertad negativa, es decir, como ausencia de interferencia, mantienen al mínimo la intervención en la sociedad civil, y con ello, en las mentalidades prevalecientes y las interacciones sociales. Ello permite la supervivencia de los estereotipos, y concentra la atención de la institucionalidad únicamente en los casos más extremos de conflicto, donde algún derecho fundamental de un sujeto perteneciente a un grupo desaventajado sea lesionado de una manera que exhiba un ánimo odioso, un prejuicio, por parte del agresor. Así, las instituciones tienden a conceptualizar como un acto de discriminación solo el enfrentamiento entre personas pertenecientes a categorías estructuralmente desaventajadas y personas que buscan manifiestamente imponerles la normatividad implícita en el estereotipo respectivo, situación procesada como una excepción y como una arbitrariedad, en lugar de ser entendida como una consecuencia esperable de mentalidades aún prevalecientes y de sus estereotipos. 
La conclusión de este diagnóstico es que enfrentar la discriminación requiere identificar las causas e instrumentos de la desventaja adscriptiva, tarea que se ve dificultada si las instituciones mantienen en la invisibilidad los factores estructurales de la misma como resultado de su adscripción a concepciones minimalistas de la discriminación, que la entienden como una excepción y una arbitrariedad. El análisis que sigue a continuación, en consecuencia, busca identificar de qué manera la jurisprudencia antidiscriminación ha conceptualizado y enfrentado el fenómeno de la desventaja adscriptiva.

\section{ESTÁNDARES CONCEPTUALES}

El lenguaje natural, medio en el que el derecho realiza sus operaciones, mantiene niveles significativos de polisemia e indeterminación. En su particular proceso de formalización, el que le da el estatus de lenguaje técnico o tecnolecto, el derecho recurre a diversas estrategias de estabilización del significado de sus términos fundamentales, convirtiéndolos en conceptos propiamente tales. Estas estrategias pueden incluir la identificación de parejas de conceptos sinónimos ("culpa lata” = "negligencia grave”) y parejas de conceptos opuestos ("culpa leve" * "cuidado ordinario"), ofrecer descripciones de las conductas que encarnan el significado del concepto ("diligencia" = "administrar un negocio como un buen padre de familia") o la elaboración de fórmulas definicionales que identifiquen los requisitos de uso de un concepto jurídico; esto es, las condiciones necesarias y suficientes que deben concurrir para etiquetar un conjunto de hechos con el término correspondiente. A esto último le denomino estándar conceptual.

¿De dónde salen estos estándares conceptuales? ¿Quién los produce? Esta es la vieja pregunta sobre quién, cómo, y con qué autoridad crea derecho. Desde luego, en algunos casos ellos provienen directamente de la pluma de los legisladores; en otros, pueden haber surgido de la labor jurisprudencial, y en algunos casos incluso pueden haber sido propuestos por académicos y posteriormente recogidos por legisladores o jueces. La identificación de los elementos del acto jurídico, la definición de delito, o el concepto de subordinación y dependencia, son ejemplos en los cuales la interacción entre materiales legislativos, aplicación jurisprudencial y análisis académico resulta en un refinamiento de los recursos conceptuales disponibles para el cumplimiento de las operaciones intelectuales de un ámbito normativo.

Un estándar conceptual adecuado debiera contener un conjunto de elementos, criterios o requisitos entendidos como condiciones necesarias y suficientes para caracterizar conductas como discriminatorias. En términos lógicos, su aplicación nos permitiría identificar un conjunto de casos (tokens) pertenecientes al tipo (type) que llamaremos "discriminación". Esto impone un constreñimiento operacional a los elementos que integren el estándar conceptual: cada uno de ellos deben ser capaces de incluir o excluir casos del conjunto típico "discriminación”. Adicionalmente, una conceptualización de la discriminación en cuanto fenómeno social como la ofrecida en la introducción, u otra que cumpla la misma función, ofrecerá un constreñimiento substantivo, en cuanto la 
conceptualización jurídica de la discriminación debiera ser capaz de ofrecer una traducción jurídica de la realidad que con esta ley se intenta transformar.

\section{El estándar Ortiz: diferenciación, arbitrariedad, lesión}

¿Cómo conceptualiza la jurisprudencia examinada la discriminación? El punto de partida, comprensiblemente, debiera ser el análisis del artículo $2^{\circ}$ de la Ley Zamudio, el que, para mayor comodidad del lector, a continuación transcribo:

Artículo $2^{\circ}$.- Definición de discriminación arbitraria. Para los efectos de esta ley, se entiende por discriminación arbitraria toda distinción, exclusión o restricción que carezca de justificación razonable, efectuada por agentes del Estado o particulares, y que cause privación, perturbación o amenaza en el ejercicio legítimo de los derechos fundamentales establecidos en la Constitución Política de la República o en los tratados internacionales sobre derechos humanos ratificados por Chile y que se encuentren vigentes, en particular cuando se funden en motivos tales como la raza o etnia, la nacionalidad, la situación socioeconómica, el idioma, la ideología u opinión política, la religión o creencia, la sindicación o participación en organizaciones gremiales o la falta de ellas, el sexo, la orientación sexual, la identidad de género, el estado civil, la edad, la filiación, la apariencia personal y la enfermedad o discapacidad.

Un primer conjunto de casos se limita a transcribir dicho artículo, sin agregar análisis ni discusiones propias. En otros casos, diversos indicios, como por ejemplo los puntos de prueba fijados por el tribunal en la resolución que recibe la causa a prueba, dan a entender que los jueces conciben la calificación de un evento como discriminatorio como un asunto fáctico, ${ }^{4}$ no como una pregunta evaluativa y, por tanto, conceptual. Ello es inadecuado en la medida en que consideremos que establecer jurídicamente qué es la discriminación no es un ejercicio empírico sino analítico: implica elaborar criterios que nos permitan clasificar y evaluar la realidad, por lo que no puede ser probado sino que debe ser argumentado sobre la base, precisamente, de un estándar conceptual que permita categorizar la conducta denunciada como discriminadora o no discriminadora.

Otras sentencias evidencian estar conscientes de esta necesidad de conceptualización para efectos de la categorización jurídica. La más temprana formulación de un estándar conceptual para la Ley Zamudio se encuentra en la sentencia Ortiz con Ministerio Público, en su considerando $11^{\circ}$. Tras haber transcrito el texto del artículo 2 de la Ley Zamudio, la sentencia señala lo siguiente:

${ }^{4}$ Ello se evidencia en la existencia de puntos de prueba como el consignado en el considerando 22 de Riesco con Servicio de Salud Ñuble, donde se reproduce la pregunta que se le dirige a un testigo en virtud del auto de prueba: "para que diga el testigo si existen actos de discriminación arbitrarias realizados en contra doña María Rebeca Riesco Aguayo por el Servicio de Salud Nuble y/ o por don Iván Renato Paul Espinoza y, en caso de existir que diga cuáles son esos actos". 
Teniendo esta sentenciadora obligación de revisar los hechos dentro del marco que la propia ley le entrega, deberá determinar la concurrencia de varias premisas fundamentales para efectos de hacer una correcta interpretación y ponderación del caso: en primer lugar, deberá establecer si existió o no una distinción, exclusión o restricción, por parte de agentes del Estado o particulares y en específico de la denunciada, para a partir de ello establecer si esta carece de justificación razonable, y resultando afirmativa su concurrencia, este tribunal deberá resolver si la distinción, exclusión o restricción causó al denunciante una privación, perturbación o amenaza en el ejercicio legítimo de los derechos fundamentales establecidos en la Constitución Política de la República o en los tratados internacionales sobre derechos humanos ratificados por Chile y que se encuentren vigentes.

En este párrafo, la sentenciadora reformula el texto de la Ley Zamudio por medio de un estándar conceptual compuesto de tres partes: primero, interroga acerca de la existencia de una determinada diferenciación; en segundo lugar, examina si ella es razonable o, por el contrario, arbitraria; en tercer lugar se pregunta respecto de si dicha conducta ha producido un perjuicio, entendido específicamente como la afectación de un derecho fundamental reconocido en la Constitución. La discriminación, entonces, sería una diferenciación arbitraria lesiva.

¿Qué implica este estándar conceptual en términos del razonamiento empleado por los tribunales? En algunos casos ha llevado a que la pregunta que los tribunales intenten responder es si la conducta denunciada es razonable. Así ocurrió con la sentencia Ortiz, en donde el tribunal concluyó que eran razonables las diferencias en el tratamiento que recibió la denuncia de violencia intrafamiliar de un hombre respecto del tratamiento que recibió la denuncia por el mismo motivo de su mujer. En otros casos, ha transformado la discusión en una interrogación concerniente a si ha habido derechos fundamentales lesionados. Así sucedió en la sentencia Carmona, donde el tribunal concluyó que la orden de no ingreso al interior de un recinto policial no constituye una restricción de los derechos fundamentales de la abogada cuya presencia constante en el recinto ocasionó dicha orden.

Esta conceptualización, como se ve, no satisface el constreñimiento substantivo postulado aquí, consistente en tematizar jurídicamente la desventaja adscriptiva. Por añadidura, otras sentencias han ofrecido variaciones del estándar Ortiz que no satisfacen el constreñimiento operativo. Por ejemplo, la sentencia Rojas con Instituto Profesional Providencia, en su considerando $12^{\circ}$, agrega un cuarto elemento adicional, consistente en que "la distinción, exclusión o restricción sea efectuada por agentes del Estado o particulares"; pero como se aprecia fácilmente, ello constituye tan solo una desagregación del elemento que he denominado como "conducta" que no satisface el constreñimiento de operatividad, pues en la medida en que exista una distinción, exclusión o restricción, términos del lenguaje natural que corresponden a casos del tipo "conducta", esto es, acción, ellas involucran lógicamente la presencia de un agente. La sentencia Majmud con Seremi OOPP, por su parte, emplea un estándar conceptual muy similar al de Ortiz, aunque estructurado de una forma distinta; su considerando $7^{\circ}$ unifica los dos primeros 
elementos de Ortiz (existencia de una conducta y falta de justificación razonable), incorpora sin modificaciones el siguiente (afectación de derechos) y agrega un tercer elemento, de manera un tanto redundante: "la falta de fundamento, falta de proporcionalidad o desviación de fin”. La sentencia no se hace cargo de explicar en qué sentido la falta de fundamento o de proporcionalidad es algo conceptualmente distinto de la falta de una justificación razonable, por lo que tampoco pareciera satisfacer el constreñimiento de operatividad.

\section{La diferenciación lesiva}

Al conceptualizar la discriminación como una tríada de elementos, la jurisprudencia hace posible llevar a cabo discusiones más circunscritas que se enfoquen en solo uno o dos elementos cuya ausencia en un caso concreto le permita rechazar que se esté frente a un caso de discriminación. Ello ocurre, por ejemplo, cuando se enfoca en el binomio diferenciación lesiva. Esto ocurre en la sentencia Castillo con Centro de Detención Preventiva de Calama. En este caso, una persona en silla de ruedas demandó a dicha institución por el tratamiento que recibió a manos de un gendarme, que no solo no le permitió ingresar al recinto sin esperar en fila su turno sino también le insultó, de la siguiente manera: "que te creí weón, creí que porque estai en una silla de ruedas, vai a entrar primero, anda hacerte la fila no más, aquí el que manda soy yo”. En su considerando 4, el sentenciador sostiene que "en estos antecedentes no existió una restricción, distinción o exclusión que privara del ejercicio de un derecho legítimo al denunciante". Lo interesante es cómo prosigue el análisis del tribunal; a juicio del mismo, "lo reclamado [por parte del demandante] obedece más bien y 'contradictoriamente' [sic] a no haberse discriminado -positivamente-", a fin de permitir al demandante "un ingreso preferente" al denunciante al Centro de Detención Preventiva en razón de su discapacidad. El sentenciador concluye observando que solo una restricción, distinción o exclusión pueden servir de sustento a aquello que es "restrictivamente lo llamado a resolverse por este tribunal, más allá de las normas de trato y respeto mutuo que deben existir en las relaciones humanas". Con ello, la sentencia anuncia que la ausencia de medidas de acceso especial para personas con movilidad reducida no constituye una exclusión. Esta conclusión resuena con el ejemplo imaginario ofrecido por la sentencia Ojeda con SERCOTEC, consistente en que un estudiante musulmán interponga una demanda por discriminación contra un establecimiento educacional que lo hubiese rechazado por su religión ${ }^{5}$; según el tribunal,

${ }^{5}$ Esto es precisamente lo que ocurrió en Silva con Colegio Chañares, con la diferencia de que la estudiante rechazada pertenecía a una familia de religión mormona. En este caso, el tribunal rechazó la demanda de discriminación, afirmando, en su considerando $6^{\circ}$, que "[d]el mérito de la prueba aportada por los denunciantes analizadas de conformidad a las reglas de la sana crítica", no queda probado "que el establecimiento denunciado haya negado la admisión de las hijas de los demandantes en razón de la religión que ambos profesan", pese a que en el mismo considerando se señala que "el colegio reconoce en su informe haber manifestado a los padres de las niñas su aprehensión ante un eventual conflicto espiritual a propósito que el Colegio se define como católico". Pero el tribunal afirma que "la norma citada exige que la negativa carezca de una justificación razonable, lo que no han probado suficientemente”, en apariencia adoptando como 
tal estudiante habría realizado a la perfección el objetivo de la Ley Zamudio pues "[d]e ello [se] trata la ley, restablecer las cosas al estado normal, no otra cosa" (énfasis añadido). ¿Qué "otra cosa" no constituye el objetivo de la ley? Al parecer, de aquello de lo que no se trata la Ley Zamudio es de reorganizar el entorno para adecuarlo a las necesidades diferenciadas de personas diferentes ${ }^{6}$.

Castillo también dio a entender otra cosa: que un funcionario público insulte a una persona con movilidad reducida no constituye una lesión relevante a ojos de la Ley Zamudio. Tampoco, según la sentencia Fuentealba con Aqueveque, lo es el insulto proveniente de un particular, en este caso un vecino que vive a pocos metros de la víctima, un menor de edad con $67 \%$ de retraso mental y epilepsia, y al que, según el relato de la madre del menor, el demandado golpeó. El considerando $10^{\circ}$ de esta sentencia reporta que los testigos "escucharon al demandado gritar algunas calificaciones en forma de burla”. El considerando $1^{\circ}$ transcribe estas "calificaciones" aportadas por los testigos: "enfermo", "habla bien”, "retrasado mental”, "tontito", "ahí viene el que no sabe hablar y que emite sonidos como animalito", "debieras caminar como perrito”. Según la sentencia, nuevamente en su considerando $10^{\circ}$, estos antecedentes "tampoco pueden configurar una perturbación o amenaza de los derechos consagrados en la Constitución Política de la República en los términos que exige la Ley 20.609”. Para la epistemología de nuestra jurisprudencia antidiscriminación el habla, por muy violento y denigrante que sea, no es un elemento relevante.

\section{3. ¿La ilegalidad como cuarto elemento necesario?}

Existe en algunas sentencias cuyo razonamiento pareciera sugerir la existencia, junto a los elementos identificados en Ortiz, de un cuarto elemento, la falta de fundamento legal de la conducta denunciada. Para estas sentencias, reminiscentes de la jurisprudencia de protección que establece como requisitos copulativos la arbitrariedad y la ilegalidad de la conducta sometida a control jurisdiccional, que una conducta esté contemplada como posible en la ley pareciera excluir la arbitrariedad. La sentencia Ojeda con SERCOTEC lo dice con todas sus letras, afirmando que "no toda distinción o restricción tiene un carácter

estándar para evaluar los antecedentes aportados por los demandantes que ellos prueben la discriminación "más allá de toda duda razonable".

${ }^{6}$ Algo parecido cabe observar a propósito de la sentencia Peña con Escuela Especial de Lenguaje. Allí, el tribunal rechazó la demanda presentada por la madre de un menor que padece epilepsia y al que se le revocó la matrícula tras haber concurrido un día al colegio demandado. En esta sentencia, el tribunal declaró que "se desestima [sic] cualquier alegación que exceda el catálogo de derechos, libertades e igualdades establecidos en su artículo 19", pues "si bien los padres tienen el derecho de escoger el establecimiento de enseñanza para sus hijos, ello no es un derecho absoluto", pues está supeditado a aquella "reglamentación interna" del colegio que regule materias, el "ingreso y permanencia de sus educandos, de lo que se desprende que la voluntad e interés de los padres deberá en todo caso sujetarse a las mismas”. Es decir, nuestra jurisprudencia considera que, respecto de una persona con necesidades especiales, el no ser incluido no es discriminación. Por añadidura, $P$ eña insiste en entender la discriminación de manera circunscrita al catálogo constitucional de derechos fundamentales; si no invoca un derecho constitucionalmente exigible, el demandante fracasará en su esfuerzo por obtener protección. 
arbitrario, es decir, pueden existir en la vida actos que atenten contra la igualdad, pero que no implican una discriminación pues están fundados por una determinada norma legal" (énfasis agregado). Ello ocurriría, ejemplifica el tribunal, "cuando una persona menor de 18 años quiere ingresar a un centro de diversión nocturno y ello le es negado por su edad, este acto que parece ser discriminatorio, no lo es, pues la ley establece que menores de 18 años de edad no pueden ingresar a estos recintos”. Lo mismo afirma la sentencia Valdebenito con Armada, cuyo considerando $16^{\circ}$ afirma que en la Ley Zamudio "aparece como sancionada la discriminación que sea arbitraria, es decir, una discriminación contraria a la justicia, la razón o las leyes, que obedece solo a la voluntad o al capricho, en otros términos, una discriminación que no encuentra sustento alguno en el ordenamiento jurídico" (énfasis agregado).

La sentencia Leal con Lan ofrece una teorización para la inclusión de este elemento a partir del texto de la propia Ley Zamudio. La sentencia señala en su considerando $3^{\circ}$ que "el artículo 6 de dicha ley dispone que no se admitirá a tramitación la acción de no discriminación arbitraria... cuando se impugnen los contenidos de leyes vigentes". Esto le permite concluir en su considerando $7^{\circ}$ que "esta Juez observa una clara impugnación de las disposiciones legales que regulan el traslado de pasajeros que pueden llegar a requerir atención o cuidado especial durante el viaje, establecidas en el DAN 382 de 2008 como también de lo dispuesto en el artículo 132 del Código Aeronáutico que regula estas materias". En consecuencia, el tribunal declaró inadmisible la acción deducida contra la línea aérea en cuestión por una mujer en silla de ruedas a la que la empresa le denegó acceso a un avión debido a no estar acompañada por otra persona ${ }^{7}$.

\section{El elemento olvidado: las categorías protegidas como expresión de desventaja estructural}

La jurisprudencia antidiscriminación en general, y el estándar conceptual ofrecido en Ortiz en particular, omite una parte importante del artículo $2^{\circ}$ de la Ley Zamudio; aquel que identifica como criterios discriminatorios "motivos tales como la raza o etnia, la nacionalidad, la situación socioeconómica, el idioma, la ideología u opinión política, la religión o creencia, la sindicación o participación en organizaciones gremiales o la falta de ellas, el sexo, la orientación sexual, la identidad de género, el estado civil, la edad, la filiación, la apariencia personal y la enfermedad o discapacidad”. Estas categorías,

${ }^{7}$ El problema en este caso es uno de prueba y evaluación. La Norma para el Transporte Aéreo de Pasajeros con Discapacidad, Enfermos o con Necesidades Especiales, DAN 382, de la Dirección General de Aeronáutica Civil, no es una norma conclusiva. Su párrafo 382.203 señala que "[u]n explotador no podrá rehusar de modo arbitrario el transporte a un pasajero afecto a esta norma, en razón de su condición”. Contiene variadas disposiciones de orientación garantista acerca del traslado de pasajeros de movilidad reducida. Y el párrafo 382.209 señala que la línea aérea excepcionalmente podrá exigir que un pasajero viaje acompañado "solamente si", entre otras hipótesis, "[t] iene una discapacidad con movilidad reducida tan severa, que sea incapaz de asistirse a sí misma en caso de emergencia de la aeronave o atender a sus necesidades fisiológicas o inmovilizada al grado de ser pasiva para su traslado". Pero el tribunal no sometió a discusión si la demandante se encontraba en tal situación de movilidad severamente reducida; y tampoco examinó adecuadamente las consideraciones normativas en tensión contenidas en el DAN 382. 
evidentemente, parecieran hacer posible una conceptualización jurídica de la desventaja adscriptiva. Pero el propio texto de la ley dificulta esta tarea; como ha observado Díaz, la redacción de la Ley Zamudio en esta materia es ambigua, pues "la expresión elegida para hacer el enlace entre la definición y las propiedades mencionadas ("en particular") no permite precisar cuál es el rol que cumplen los tales criterios en la configuración de una discriminación y da lugar a diversas interpretaciones" ${ }^{\prime}$. ¿Ha logrado la jurisprudencia antidiscriminación precisar esta relación? La respuesta, si nos concentramos en el estándar Ortiz, pareciera ser más bien que aquellas categorías no desempeñan un rol esencial en el análisis conceptual de la discriminación.

Una confirmación indirecta de esta ausencia de la desventaja adscriptiva pareciera encontrarse en la sentencia Easton con Federación de Rodeo Chileno. Es factible señalar que esta es una de las doce sentencias, de cuarenta y dos dictadas hasta la fecha, que han acogido una demanda por discriminación en virtud de la Ley Zamudio. Y, ¿cuál es el contenido de este litigio? El demandante, un ingeniero forestal dueño de caballos corraleros, exige que la Federación de Rodeo Chileno levante la sanción que existe en su contra y que le impide participar del torneo de rodeo. Dicha sanción, según consigna la sentencia en su parte expositiva, fue aplicada por el Tribunal Supremo de Disciplina de la Federación del Rodeo Chileno "con motivo de las expresiones injuriosas que [el demandante] vertió en contra de miembros de dicha Federación”. La sentencia también informa que el demandante presentó anteriormente un recurso de protección ante la Corte de Apelaciones de Santiago, que fue rechazado; que el demandante obtuvo que la Subsecretaría de Justicia emitiese una resolución cuestionando la competencia del Tribunal de la Federación; y que la demandada presentó ante el $2^{\circ}$ Juzgado de Letras de Santiago una acción judicial de declaración de mera certeza dirigida contra la Subsecretaría y el demandante, a fin de despejar las dudas respecto de la competencia del Tribunal de la Federación de Rodeo.

Hasta aquí es posible observar dos cosas. La primera, que se trata de un asunto latamente discutido ante otras instancias jurisdiccionales. La segunda, que no existen en este conflicto sujetos que intuitivamente caracterizaríamos como víctimas habituales de discriminación, que requieran de la protección de un instituto jurídico especial. Pero como el tribunal no se pregunta por el rol que cumplen en el litigio antidiscriminación las categorías señaladas en el artículo $2^{\circ}$ de la Ley Zamudio, entonces no ve ningún problema en que el "corralero" demande a la Federación por discriminación.

El tribunal utiliza el estándar Ortiz, aunque de manera menos explícita que en otras sentencias. El considerando $7^{\circ}$ de la sentencia transcribe en su integridad el artículo 2 de la Ley Zamudio; los tres elementos de Ortiz se identifican en los considerandos $8^{\circ}$ (diferenciación), $9^{\circ}$ (arbitrariedad), y $10^{\circ}$ (perjuicio). La parte resolutiva evidencia que su propósito central ha sido determinar la racionalidad de la conducta denunciada: ella "declara que ha existido discriminación arbitraria al privar al demandante de desarrollar el rodeo y de inscribir los caballos de su criadero, sin existir una justificación para

${ }^{8}$ Díaz, I., "Ley chilena contra la discriminación. Una evaluación desde los derechos internacional y constitucional", en Revista Chilena de Derecho, vol. 40, 2013,p. 649. 
mantener dicha medida después de lo ordenado por el Ministerio de Justicia”. Así, el tribunal termina fallando a favor del demandante.

Este caso es muy importante, pues nos permite percibir la continuidad entre la tradicional jurisprudencia constitucional respecto de igualdad y la jurisprudencia existente hasta el momento en la Ley Zamudio. Es importante anotar, volviendo a mi primera observación relativa a las estrategias de estabilización conceptual, que dicha jurisprudencia ha históricamente empleado la estrategia consistente en identificar un par de conceptos sinónimos (igualdad = no discriminación arbitraria) de la que se deduce un par de conceptos antónimos (igualdad $\neq$ arbitrariedad), y nuevos pares de conceptos sinónimos (arbitrariedad $=$ capricho). Así queda claro en aquella clásica sentencia de la Corte de Apelaciones de Santiago según la cual el acto arbitrario es aquel "contrario a la justicia, la razón o las leyes, producto de la sola voluntad o capricho del que lo comete"' equivalente a "un actuar irracional o caprichoso, esto es, con voluntad no gobernada por la razón".

Si nos tomamos en serio la nube de conceptos en torno a la cual se construye la jurisprudencia constitucional de igualdad, debiéramos concluir que ella consiste en un control jurisdiccional de la racionalidad de la conducta. Si es que algo pudiese ser dicho sobre el estándar Ortiz es que representa un avance en términos de especificidad analítica respecto de la acumulación de sinónimos y antónimos que ofrece la jurisprudencia constitucional concerniente a igualdad. Lo que es admisible lamentar es que ello no contribuya a la teorización de la desventaja adscriptiva, y con ello, a la lucha contra la discriminación que experimentan los integrantes de grupos histórica y estructuralmente desaventajados.

Pocas sentencias permiten asignarle algún rol efectivo a las categorías del artículo $2^{\circ}$. Sentencias como Ojeda con SERCOTEC sugieren un abordaje, pero no lo desarrollan de una manera decisiva; dicha sentencia señala que "una discriminación es arbitraria cuando se funda en motivos tales como" los establecidos en el artículo $2^{\circ}$, "es decir, que la discriminación no tenga fundamento plausible alguno”. Pero esta afirmación no jugó ningún papel en el razonamiento jurídico de dicha sentencia; es obiter dictum, bastante inconducente, por lo demás, en la medida en que no se hace cargo de la discusión que genera el inciso $3^{\circ}$ del mismo artículo, como ya tuve oportunidad de observar respecto del ejemplo del estudiante musulmán ofrecido por la misma sentencia.

La sentencia Fuentealba con Aqueveque, por su parte, recurre a la categoría relevante, en este caso la discapacidad mental del menor de edad víctima de agresiones verbales y físicas, pero tan solo para reprocharle a la demandante, la madre del menor, no haber sido capaz de demostrar que la golpiza, se deba directamente a una distinción hecha con motivo de la discapacidad que sufre. ¿Qué quería la sentencia que fuese demostrado? ¿Un vínculo causal entre ciertos hechos (la discapacidad mental del menor), ciertos estados mentales del agresor (el ánimo lesivo u odiosidad del agresor), y ciertos resultados fácticos (la golpiza)? Es esencial sugerir que la construcción de estas relaciones corresponde más bien a una labor del razonamiento judicial que a un asunto que corresponda a los litigantes probar.

\footnotetext{
${ }^{9}$ Sentencia de 5 de marzo de 1992, en Repertorio de Legislación y Jurisprudencia Chilenas (1992), p. 9.
} 
Las categorías aparecen en un sentido un poco más relevante, constriñendo el tipo de reclamos que pueden ser canalizados mediante la Ley Zamudio, en la sentencia Morandé con CONICYT. En este caso, un abogado domiciliado en Las Condes en vías de cursar un programa de maestría en derecho en la Universidad de California en Berkeley, demandó a la Comisión Nacional de Investigación Científica y Tecnológica reclamando el haber sido excluido arbitrariamente, esto es, sin fundamento razonable, del proceso de postulación a una beca de estudios.

La sentencia se aparta del estándar conceptual Ortiz en su considerando $5^{\circ}$. Allí sostiene que "son presupuestos de la acción de que se trata" los siguientes: primero, que exista una conducta; segundo, que ella "carezca de justificación razonable"; tercero, que ella lesione titularidades valiosas; cuarto, que la conducta se funde "en motivos tales como" aquellas categorías de sujetos señaladas en el artículo 2 de la Ley Zamudio. Evidentemente, la situación denunciada por el demandante en este caso no puede ser subsumida dentro de ninguna de aquellas categorías. Así lo entiende la sentencia, la que señala en su considerando $12^{\circ}$ que "el acto que por esta vía se impugna, de modo alguno puede configurar una discriminación arbitraria", puesto que "la discriminación debe basarse en cierto criterio de distinción, exclusión, restricción o preferencia, criterios que constituyen condiciones individuales o sociales que remarcan algún grado de identidad", como ocurre con las categorías identificadas en la Ley Zamudio. Y, continúa la sentencia, "[s]i bien dichas categorías no son excluyentes de otra, el actor no funda tal discriminación en ninguna de las categorías antes establecidas ni en otras”. Ella concluye afirmando, en una línea argumentativa que se aparta de la comprensión de la acción antidiscriminación como control de racionalidad de la conducta, que "resulta un presupuesto insoslayable de la acción en estudio que la distinción, exclusión, restricción o preferencia hecha por una persona o institución se funde en alguna de las categorías que establece esta ley u otra”.

Lo que la sentencia no explora, y que es imprescindible a efectos de construir una jurisprudencia antidiscriminación efectiva, es qué es lo distintivo o específico de esas categorías, especificidad que eventualmente permitiría identificar otras categorías protegidas. Como se sabe, las becas que otorga la CONICYT otorgan una bonificación en su puntaje de postulación a las personas que acrediten pertenecer a una etnia indígena. ¿Podría invocar la protección de la Ley Zamudio una persona que, en un proceso de postulación a dichas becas, no reciba bonificación en su debido a que no pertenece a dichas etnias? Dicha persona estaría, efectivamente, fundando su reclamo en que la distinción hecha por CONICYT encuentra su razón de ser, causa o fundamento en "condiciones individuales o sociales que remarcan algún grado de identidad”.

Curiosamente, la única sentencia que pareciera comprender esta problemática es la sentencia Carvajal con Duarte, sentencia que acoge la demanda por discriminación presentada por una funcionaria municipal desvinculada por su ideología política. En el caso de dicha sentencia, ello no se logra recurriendo a la teoría del derecho antidiscriminación, ni a la reflexión sociológica que se encuentra detrás de ella. Señala la sentencia en su considerando $10^{\circ}$ que "conviene tener presente que según el diccionario de la Real Academia de la Lengua Española, discriminación puede ser definido como 'acción 
y efecto de discriminar', y a su vez el término 'discriminar' es conceptualizado como 'Dar trato de inferioridad a una persona o colectividad por motivos raciales, religiosos, políticos, etc", definición de la cual la sentencia concluye "que para la existencia de un acto discriminatorio se deben ejecutar actos positivos que menoscaben al sujeto pasivo o víctima de tales hechos".

Me parece que la construcción de una jurisprudencia antidiscriminación efectiva debe profundizar estas reflexiones, situando el objeto de su regulación -esto es, la discriminación- en su genuino contexto; el de la lucha histórica de diversas categorías de sujetos por poner fin a su condición de subalternidad, subordinación o desventaja. Esto involucra reconocer las asimetrías que existen al interior de cada una de las categorías identificadas en el artículo $2^{\circ}$. Por el momento no ahondaré aquí en lo que ello significa conceptualmente. Pero la construcción de una teoría del derecho antidiscriminación que se haga cargo de estos aspectos constituye una tarea ineludible para efectos de construir una jurisprudencia antidiscriminación efectiva.

\section{CARGAS PROCESALES}

Por cargas procesales me refiero a la carga de probar los hechos que se invocan como existentes, y a la carga de persuadir al tribunal del carácter discriminatorio o no discriminatorio de los hechos en cuestión. Me referiré, de manera más resumida, a la carga de la prueba y la carga de la justificación.

La asignación de estas cargas refleja qué estado de cosas está jurídicamente protegido. La atribución de la obligación de probar la existencia de un hecho o la inexistencia del mismo, y de soportar el peso de no lograr dicha prueba, es una regla que determina el default de un determinado ámbito normativo. En otras palabras, el resultado práctico de dicha obligación es que ella determina quién paga por el costo de la incertidumbre en la forma de una sentencia condenatoria, en caso de que no existan pruebas determinantes en un sentido u otro.

Ahora bien, el "sentido común" contenido en nuestra cultura jurídica parte de la base de que corresponde probar un hecho a quien lo alega. Sin embargo, el sentido protector del derecho laboral y del derecho antidiscriminación ha evidenciado que en los casos de sujetos situados en una situación fáctica de vulnerabilidad, las dificultades de reunir pruebas vuelven aconsejable el trasladar ciertas cargas a los demandados. En Estados Unidos, esta posibilidad es conocida como el desplazamiento McDonnell Douglas, en razón de la primera sentencia de la Corte Suprema que declaró que, en el caso de que un demandante ofreciera pruebas que prima facie sugirieran la existencia de prácticas de contratación discriminatorias, la responsabilidad de articular alguna razón legítima y no discriminatoria debe desplazarse al demandado; para decirlo en las palabras de la Corte, burden then must shift ${ }^{10}$. La jurisprudencia de la Corte Europea de Justicia recogió

${ }^{10}$ McDonnell Douglas Corp. v. Green 411 U.S. 792, 802 (1973). 
esta posibilidad en 1988 en el caso Danfoss ${ }^{11}$, posteriormente regulada en la Directiva 97/80/CE del Consejo de la Unión Europea, de 1997, relativa a la carga de la prueba en los casos de discriminación por razón de sexo, y cuyo artículo $4^{\circ}$ contempla la posibilidad de que ante "hechos que permitan presumir la existencia de discriminación directa o indirecta, corresponda a la parte demandada demostrar que no ha habido vulneración del principio de igualdad de trato”. En nuestra legislación, el artículo 493 del Código del Trabajo contempla la posibilidad de que, existiendo "indicios suficientes de que se ha producido la vulneración de derechos fundamentales", se traslade al demandado el deber de "explicar los fundamentos de las medidas adoptadas y de su proporcionalidad". La Ley Zamudio, en tanto, no contempla explícitamente esta posibilidad.

\section{La asignación de las cargas procesales en la jurisprudencia sobre Ley Zamudio}

La jurisprudencia respecto de la Ley Zamudio, en una proporción abrumadora, preserva las reglas tradicionales acerca de atribución de la carga de la prueba; es decir, aquella que sostiene que incumbe probar a quien afirma la ocurrencia de un hecho, con lo que ella recae las más de las veces en la parte demandante. El resultado es que lo más frecuente sea que los juicios seguidos en virtud de la Ley Zamudio concluyan por falta de prueba.

Si bien abundan los ejemplos, me limitaré a identificar el razonamiento ofrecido por una sentencia, Peña con Tamayo. Esta sentencia articula en su considerando 8 la concepción tradicional de la asignación de las cargas procesales, afirmando que corresponde a la parte demandante, "de conformidad a las normas reguladoras de la prueba, acreditar los hechos expuestos en la demanda" -esto es, la carga de la prueba- y "la forma en que estos habrían configurado una distinción, exclusión o restricción arbitraria” -esto es, la carga de la justificación-, así como "que esta discriminación se hubiere debido a su orientación sexual o identidad de género, y la forma en que esta situación habría provocado una privación, perturbación o amenaza en el ejercicio de sus derechos fundamentales".

¿Hay alguna sentencia que desplace alguna carga procesal a la demandada? Efectivamente: la sentencia Easton con Federación de Rodeo. Ella emplea embrionariamente estrategias de análisis que han de ser parte de una efectiva jurisprudencia antidiscriminación. Una de ellas es la inversión de la carga de la justificación de la conducta denunciada como discriminatoria; así, en su considerando $11^{\circ}$, la sentencia afirma que "correspondía a la demandada justificar la razonabilidad de mantener la sanción impuesta al demandante". Otra es la estrictez en la evaluación de las justificaciones ofrecidas por la demandada, lo que se evidencia en el juicio que formula la sentencia en su considerando $13^{\circ}$, donde desestima los argumentos de fondo ofrecidos por la demandada para no acatar la resolución de la Subsecretaría de Justicia sosteniendo que "[e]l hecho de no compartir lo decidido por la autoridad administrativa no es justificación razonable para no acatar las instrucciones impartidas, lo que torna en arbitrario el actuar de la demandada".

${ }^{11}$ Asunto 109/88 Danfoss [1989] ECR I-3199. 
Algo similar ocurre en Riesco con Servicio de Salud Ñuble; tras dar por probada la ocurrencia de los hechos denunciados por la demandante en su considerando 19, dicha sentencia procede en su considerando 20 a afirmar que "corresponde analizar ahora, si la actitud de la denunciada puede considerarse razonable", concluyendo que "la denunciada, no ha justificado (como le correspondía), su actuación, en el marco de ninguna de las garantías constitucionales mencionadas en el artículo $2^{\circ}$, ni ha acreditado, a juicio del sentenciador, causa legítima”.

Por último, en Majmud, y quizás con mayor claridad teórica, la sentencia elabora una justificación de la inversión de la carga de la justificación, en su considerando $12^{\circ}$ :

De conformidad con lo dispuesto en el artículo 1698 del Código Civil y teniendo especialmente en consideración lo referido en el informe de la Comisión de Constitución, Legislación y Justicia, como se lee en la página 577 de la historia de la Ley 20.609, establecida la existencia de un hecho discriminatorio que vulnere los derechos fundamentales referidos en el artículo segundo, no puede objetivamente existir un acto de discriminación sancionado, sino que se produce un traslado de la carga probatoria, correspondiendo al denunciado el acreditar la racionalidad o fundamentación de su actuar. Con lo anterior, ha correspondido al Fisco de Chile el acreditar que se encuentra dentro de aquellos casos en que la Ley 20.609 admite las distinciones, exclusiones o restricciones prohibidos. Sin embargo, dicha probanza no ha sido rendida, ni tampoco ofrecida $[\ldots]$.

Sin embargo, ni aún en Easton, Riesco o Majmud existe desplazamiento de la carga de la prueba. Los sentenciadores parecieran haber adoptado una solución intermedia, similar a la de nuestro Código del Trabajo, en que tras asignar al demandante la carga de la prueba, atribuyen al demandado la carga de la justificación.

\section{La evaluación de la prueba: ¿acucioso con el demandante o con el demandado?}

La primera sentencia pronunciada en un caso tramitado de acuerdo a la Ley Zamudio, Zapata con Motel Marín 014, constituyó un caso tremendamente afortunado en materia de prueba, pues en este caso un representante del motel denunciado confesó ante cámaras de televisión que efectivamente se había expulsado de dicho recinto a las demandantes por su condición de lesbianas ${ }^{12}$.

Con posterioridad a esta sentencia, parece posible apuntar a la existencia de dos niveles distintos de acuciosidad en materia probatoria. Una de ellas es acuciosa y exigente con las pruebas aportadas por la demandante; la otra es acuciosa y exigente con las pruebas aportadas por la demandada. Mencionaré dos ejemplos de la línea jurisprudencial que evalúa exigentemente las pruebas de la demandante. El primero de ellos corresponde a la

\footnotetext{
${ }^{12}$ Véase Muñoz, F., "No a 'separados pero iguales' en Chile: un análisis del derecho antidiscriminación chileno a partir de su primera sentencia”, en Estudios Constitucionales, vol. 11, 2013.
} 
sentencia Suárez con Compañía de Bomberos, en donde una mujer alega que su postulación a la compañía de bomberos en cuestión fue rechazada por los integrantes de la misma debido a su género. La sentencia recoge la evidencia que demuestra que la demandante cumplió con los requisitos formales para incorporarse a la Compañía de Bomberos demandada. Incluso, se reporta el testimonio de una testigo a la que integrantes de la Compañía le habían advertido que no podría incorporarse una mujer bombero. Así y todo, la sentencia desecha este testimonio afirmando que sus palabras no dan cuenta "de haber estado presente en el proceso de votación o haber participado en él a fin de poder señalar que al momento de la decisión se utilizó el criterio por ella señalado para excluir a la postulante a Bombero de la Compañía, por lo que no es posible atribuirlo más que a un rumor que carece de elementos sólidos de sustentación que permitan darle apoyo para formarse la convicción en ese sentido" (considerando 15). La sentencia, en cambio, razona así en su considerando 16:

Que, constituyendo, en efecto, la votación final de incorporación un acto de discrecionalidad por parte de los votantes, quienes si bien no aparecen fundamentando su voto, toda vez que tampoco lo exige así el Reglamento, no es posible atribuir una intención negativa a aquellos votos en contra de la incorporación, salvo prueba de ello, lo que no ocurre en la especie, toda vez que aceptar lo contrario implicaría presumir la discriminación arbitraria en el actuar de los Bomberos sufragantes o bien, suponer intencionalidad discriminatoria cada vez que alguien, habiendo superado diversas etapas en un proceso de selección, finalmente no sea seleccionado en la instancia.

En realidad, lo que la sentencia hace aquí es exigir a la demandante probar la intencionalidad discriminatoria. Es importante señalar que, en el derecho antidiscriminación norteamericano, la exigencia de demostrar una intención discriminatoria (discriminatory intent) surge, respecto de la legislación y otras formas de acción estatal, en la sentencia Washington v. Davis ${ }^{13}$; sentencia cuyo efecto concreto fue desplazar el escrutinio antidiscriminación desde los efectos de las prácticas cuestionadas -foco de la jurisprudencia inspirada en la sentencia Griggs ${ }^{14}$ - a las intenciones subjetivas, los estados mentales, de quienes las adoptaron. Naturalmente, el ámbito o esfera de protección del derecho antidiscriminación norteamericano se redujo con el estándar Washington ${ }^{15}$.

La sentencia Fuentealba con Aqueveque constituye otro caso en que el tribunal es considerablemente acucioso con la parte demandante. Dicha sentencia rechazó la demanda presentada por la madre de un menor con retraso mental, quien denunció agresiones físicas y verbales de carácter discriminatorias dirigidas contra su hijo por un vecino. En este caso se rindió confesional, esta dio como resultado, según señala la sentencia en su

\footnotetext{
${ }^{13}$ Washington v. Davis, 426 U.S. 229 (1976)

${ }^{14}$ Griggs v. Duke Power Co., 401 U.S. 424 (1971).

${ }^{15}$ Véase Siegel, R., "Race-Conscious But Race-Neutral: The Constitutionality of Disparate Impact in the Roberts Court", en Alabama Law Review, vol. 66, 2015, pp. 656-665.
} 
considerando $1^{\circ}$, que el demandado reconoció "que tiene conocimiento que Juan Orellana Fuentealba sufre de discapacidad mental y que ha tenido contacto frecuente con Juan Orellana Fuentealba, por ser vecino de su población”, así como que "el demandado no aportó prueba alguna al proceso” (considerando $2^{\circ}$ ). Incluso más, la demandante aportó "copias de certificado de atención de urgencia y sicológica de fs. 28 y 29, que refieren haber sido [el menor] víctima de lesiones leves el día 10 de diciembre de 2013, y [que] el 19 de febrero de 2014 [el menor] ingresa a solicitud de la madre a tratamiento psicológico en el área de salud mental por la agresión física y psicológica sufrida”. Pero la sentencia concluye en su considerando $8^{\circ}$ que los documentos aportados por la demandante "dan cuenta efectivamente de una afectación física de su hijo pero en ningún lado manifiestamente expresan que el autor de esas lesiones sea el demandado, y tampoco ha acreditado que tal situación haya sido conocida por un Tribunal penal de esta ciudad, como así lo expresara una de sus testigos, por lo que esa prueba es insuficiente para que esta Juez estime en primer lugar que el demandado ha sido el autor de las lesiones leves que le fueron ocasionadas". Por añadidura, agrega la sentencia que "tampoco se ha acreditado que la afectación física de su hijo se deba directamente a una distinción hecha con motivo de la discapacidad que sufre, por lo que no existe nexo causal entre las lesiones, su autoría, y menos aún para la aplicación de esta ley especial que tiene un objeto preciso y claro que debe en todo caso acreditarse con los medios de prueba legal suficientes para tener por configurada la discriminación” (considerando $9^{\circ}$ ).

Veamos ahora dos sentencias que toman un camino distinto, el de ser acuciosas en su evaluación de las pruebas ofrecidas por la demandada. La sentencia Díaz con Armada ofrece un ejemplo de ello. En su considerando 13, la sentencia evalúa el informe psicológico elaborado por la Jefe del Servicio de Psiquiatría de la Armada de Chile, y concluye que aquel "no señala que el actor sufra enfermedad alguna", y que si bien "el demandante tiene un perfil atípico, asintomático y defensivo, lo que sugiere negación, alexitimia o asperger", ello a lo más sería "un indicio de una patología, la cual, de manera alguna es posible tenerla por establecida". Por ello, concluye que dicho informe no demuestra la existencia de una enfermedad que autorice el dar de baja al demandante, sino que tan solo "hace una descripción de la personalidad del actor, la que, aun cuando presente ciertas observaciones, no aparece revestida de argumentos que permitan concluir inequívocamente que estamos frente a una enfermedad declarada incurable o el sufrimiento de alguna inutilidad señalada en la ley". Por ello, concluye que "de conformidad al cúmulo de probanzas allegadas al proceso, fluye que la decisión de retiro del demandante no encuentra el debido sustento jurídico". Si bien el Director General del Personal de la Armada tenía la facultad para disponer el retiro del reclamante, el ejercicio de tal facultad "tenía que fundarse en una causa legal efectiva".

La sentencia García con INDAP ofrece también un ejemplo de evaluación acuciosa de la prueba. En su considerando $18^{\circ}$, ella anuncia que "los antecedentes probatorios que se analizarán seguidamente, valorados conforme las reglas de la sana crítica permiten a esta sentenciadora arribar a la convicción que la motivación del acto administrativo que puso término al contrato de la denunciante obedeció a su ideología u opinión política”. La sentencia examina críticamente la explicación ofrecida por la denunciada, la que indica 
como motivación del término del contrato "razones de estructuración de las políticas de fomento de Indap regional y por un tema presupuestario", explicación que le parece insuficiente, y concluye en que hay una "carencia de motivación razonable del acto", "debiendo suponerse en consecuencia razones ajenas, esto es, la adhesión política de la denunciante, conocida en el servicio, como han declarado los testigos de la denunciante". En este caso, la sentencia se muestra dispuesta a evaluar críticamente la relevancia de las explicaciones ofrecidas, así como a construir inferencias a partir de la prueba aportada.

\section{El estándar de justificación: ¿qué es razonable?}

En los detalles está el diablo, dice el dicho. La revisión de las diversas argumentaciones consideradas por los tribunales como justificación razonable pareciera darle la razón a esa afirmación. Algunas sentencias parecen anunciar interesantes y sofisticados análisis, que finalmente no son ofrecidos. Ortiz con Ministerio Público, por ejemplo, afirma en su considerando $19^{\circ}$ que para calificar un acto como discriminación arbitraria, "la doctrina señala que no solo debemos realizar un 'test de razonabilidad', sino que, si la situación lo amerita, deberá adecuarse a criterios doctrinarios de 'proporcionalidad' (es decir, que los actos o normas impugnados se encuadren dentro del espíritu general de la legislación, y con los principios y valores de la sociedad) o de 'adecuación' (cuando una distinción razonable pudiere ser discriminatoria en atención a otros factores de carácter político, histórico o cultural)”. Esta sentencia, precisamente, se prestaba para tal análisis, porque lo que estaba en discusión era la acusación de un hombre de haber sido víctima de una discriminación de género debido a que su demanda por violencia intrafamiliar no había sido investigada con la diligencia que le parecía necesaria. Y precisamente, pudiendo haber entrado en un interesante análisis acerca de los "principios y valores de la sociedad" y referido a distinciones que de razonables pasen a ser discriminatorias "en atención a otros factores de carácter político, histórico o cultural”, todo ello eventualmente incorporando un enfoque de género a la evaluación de estas circunstancias, la sentencia concluyó en cambio, de manera formalista y abstracta, que "los parámetros a los que se ajustaron las investigaciones de la Fiscal demandada en las causas agrupadas eran estándares" (considerando $20^{\circ}$ ).

Ya hemos visto que la invocación de la legalidad a menudo basta como causal justificante, al punto que en sentencias como Leal con Lan ella conduce al rechazo de la tramitación de la causa. Otras sentencias evidencian que la evaluación que los jueces hacen de las justificaciones ofrecidas por las demandadas pareciera revelar una cierta tendencia a aceptar de manera acrítica las respuestas que se sustenten en antecedentes contractuales, así como en los dichos de alguna autoridad. Ejemplo de la fácil aceptación de antecentes contractuales como excusa lo ofrece la sentencia López con INE, en esta una trabajadora a honorarios es despedida, según se le confirma verbalmente, por su situación de gravidez. En este caso, aquello que fácilmente se acepta como justificación suficiente corresponde a las reglas de contratación a honorarios fijada, como ocurre en prácticamente toda prestación de servicios a honorarios, por la parte más firme, es decir, la institución demandada. En este caso, la sentencia le reprocha a la demandante, en su 
considerando $13^{\circ}$, que "tratándose la denunciante de una prestadora de servicios para la institución denunciada desde el año 2011, debió conocer las políticas reguladoras de la institución”. En tonos que recuerdan a la sentencia Lochner de la Corte Suprema de Estados Unidos, ${ }^{16}$ el tribunal concluye aseverando que la institución demandada, "en concepto de este Tribunal actuó conforme al ordenamiento jurídico aplicable al contrato de prestación de servicios a honorarios, celebrado con plena voluntad de las partes, por aplicación al principio de autonomía de la voluntad que rigió la contratación, en la que ambas partes obraron con plena capacidad" (considerando $13^{\circ}$ ).

Ejemplo de la fácil aceptación de aquello que diga la autoridad como excusa, en tanto, lo ofrece la sentencia Peña con Escuela Especial de Lenguaje. Allí, el tribunal rechazó la demanda presentada por la madre de un menor que padece epilepsia, y al que se le revocó la matrícula tras haber concurrido un día al colegio demandado. Como reporta el considerando $6^{\circ}$, la demandada reconoció "haber cancelado la matrícula del menor" en cuestión "por razón de enfermedad”, situación que el colegio justificó por "haber obrado de tal manera luego de [haber] consultado al Coordinador de Educación Especial del Ministerio de Educación”. ¿El Coordinador de Educación Especial no puede actuar de manera poco razonable? Claro, uno siempre podría afirmar, inspirándose en la doctrina Chevron de la Corte Suprema norteamericana, ${ }^{17}$ que se trata de una autoridad administrativa que merece deferencia por parte del tribunal en virtud de su experticia, de su autoridad epistémica. El problema -además del hecho de que en casos de discrete and insular minorities ${ }^{18}$, la jurisprudencia norteamericana emplea un escrutinio estricto de la conducta estatal- es que en este procedimiento no hubo aportaciones fundadas, argumentos o antecedentes técnicos por parte de la autoridad. Tan solo se hizo referencia a la existencia de un procedimiento administrativo, substanciado por la propia autoridad administrativa, que concluyó "sin reproche alguno que diga relación con acto discriminatorio arbitrario de ninguna especie". El lenguaje que emplea la propia sentencia evidencia esta aceptación acrítica de la intervención de la autoridad: "más allá de la procedencia o no de la decisión de exclusión -revocación de matrícula- adoptada, esta no fue arbitraria en la medida que reconoce sustento atendible y no una mera decisión caprichosa e infundada de carácter unilateral" (considerando $34^{\circ}$ ). Claro, si las dos alternativas existentes para la sentenciadora son que la decisión tenga "sustento atendible", lo que es igual a decir sustento "probable", "plausible", "mínimamente razonable", o bien que ella sea "caprichosa e infundada", entonces resulta muy, pero muy fácil absolver.

A la inversa, otras sentencias logran aplicar criterios exigentes a la hora de evaluar la razonabilidad de la conducta denunciada. Un ejemplo es Majmud con Seremi OOPP. En este caso, en el que una directora de un jardín infantil ha sido destituida de su cargo tras regresar a sus funciones después de un embarazo, la sentencia elabora un

\footnotetext{
${ }^{16}$ Lochner v. New York, 198 U.S. 45 (1905).

${ }^{17}$ Chevron v. Natural Resources Defense Council, 467 U.S. 837 (1984).

${ }^{18}$ United States v. Carolene Products Company, 304 U.S. 144, 152 n. 4 (1938).
} 
interesante cotejo con situaciones similares a la de la demandante. Observa la sentencia que "no habido igualdad de trato, desde ninguna de las vertientes posibles, respecto de la actora" a la luz del "único punto de comparación posible", esto es, "la anterior directora, que en idéntica situación jurídica que la actora, esto es siendo ambas mujeres contratadas en el mismo grado, con idénticas remuneraciones, para trabajar como educadores de párvulos”. Observa la sentencia que la anterior directora duró 20 años en el cargo, con lo que "puede decirse con certeza que no constituye una designación eventual y transitoria”, de modo que "es dable esperar por la actora idéntica situación". Incluso más, llega a afirmar la sentencia que no solo ha habido una desigualdad en el trato, sino también que "se ha excluido a la actora de modo desigual, al desatender su condición de falta de equiparidad que ameritaba un trato desigual de partida, atendida su condición de mujer embarazada" (considerando $10^{\circ}$, énfasis en el original). La sentencia concluyó condenando.

\section{CONCLusiones}

La academia ha formulado diversas críticas al texto de la Ley Zamudio, apuntando a deficiencias en su redacción que hacen probable su inefectividad, y sugiriendo reformas a su texto. ${ }^{19} \mathrm{El}$ análisis realizado en este trabajo da sustento a la idea de que la Ley Zamudio necesita ser reformada para clarificar que su función es combatir la desventaja estructural protegiendo a los sujetos estructuralmente desaventajados, así como para establecer que la carga de la prueba debe quedar en ciertas situaciones de cargo del demandado.

Así y todo, a mi juicio, más urgente aún, y más desafiante, es que los jueces incorporen a su cultura jurídica la conciencia de la siguiente realidad: que la lucha contra la discriminación entendida como un fenómeno social exige un tipo de racionalidad jurídica protectora, similar a la que se le adscribe al derecho laboral. Esto involucra cambios profundos en la cultura jurídica de nuestra judicatura. Fundamentalmente, hace falta la construcción de una disciplina jurídica que dé sustento a la lectura prodiscriminado que aquí se propugna. Tal construcción debiera integrar las diversas áreas de nuestro sistema jurídico que actualmente están vinculadas a la lucha contra la discriminación, incluyendo leyes relacionadas con categorías específicas de sujetos como las personas en situación de discapacidad o los pueblos indígenas. Tal dogmática de los grupos desaventajados es una tarea que, por el momento, queda pendiente. Este trabajo, al menos, evidencia su necesidad.

${ }^{19}$ Así, por ejemplo, Díaz (n. 7), Vial, T., "La nueva Ley Antidiscriminación: propuestas para avanzar en su perfeccionamiento", en Anuario de Derechos Humanos (Universidad de Chile), vol. 9, 2013, pp. 183-191; Díaz de Valdés, J., “¿Es la Ley Zamudio Verdaderamente una Ley General Antidiscriminación?”, en Revista Actualidad Jurídica, vol. 28, 2013. 


\section{BIBLIOGRAFÍA}

Atria, F., Los Peligros de la Constitución (1997), Universidad Diego Portales, Santiago, 1997.

Díaz, I., "Ley chilena contra la discriminación. Una evaluación desde los derechos internacional y constitucional", en Revista Chilena de Derecho, vol. 40 (2013).

Díaz de Valdés, José Manuel, “¿Es la Ley Zamudio Verdaderamente una Ley General Antidiscriminación?”, Revista Actualidad Jurídica, vol. 28 (2013).

MuÑoz, F., "La Ley Zamudio en acción: sentencias de primera instancia sobre acción antidiscriminación emitidas entre diciembre de 2012 y marzo de 2015”, en Anuario de Derecho Público (Universidad Diego Portales), vol. 6, 2015.

MuÑoz, F., "No a 'separados pero iguales' en Chile: un análisis del derecho antidiscriminación chileno a partir de su primera sentencia", en Estudios Constitucionales, vol. 11, 2013.

Siegel, R., "Race-Conscious But Race-Neutral: The Constitutionality of Disparate Impact in the Roberts Court”, en Alabama Law Review, vol. 66, 2015.

Vial, T., "La nueva Ley Antidiscriminación: propuestas para avanzar en su perfeccionamiento", en Anuario de Derechos Humanos (Universidad de Chile), vol. 9, 2013.

\section{Sentencias estudiadas}

$3^{\circ}$ Juzgado de Letras de Santiago, rol 17314-2012, Zapata con Motel Marín 014, sentencia de 5 de diciembre de 2012.

$1^{\circ}$ Juzgado de Letras de La Serena, rol 3133-2012, Pizarro con SERNAM, sentencia de 19 de marzo de 2013.

$22^{\circ}$ Juzgado de Letras de Santiago, rol 20750-2012, Ortiz con Ministerio Público, sentencia de 25/06/2013.

$15^{\circ}$ Juzgado de Letras de Santiago, rol 26206-2012, Morandé con CONICYT, sentencia de $18 / 07 / 2013$.

$2^{\circ}$ Juzgado de Letras de Calama, rol 1502-2012, Castillo con Centro de Detención Preventiva de Calama, sentencia de 22/07/2013.

$1^{\circ}$ Juzgado de Letras de Coyhaique, rol 1325-2013, Martínez con Servicio de Salud, sentencia de $16 / 10 / 2013$.

$1^{\circ}$ Juzgado de Letras de Rancagua, rol 9091-2013, Osorio con Concejales de Municipalidad de Graneros, sentencia de 25/11/2013.

Juzgado de Letras de Lautaro, rol 318-2012, Easton con Federación de Rodeo Chileno, sentencia de $05 / 12 / 2013$.

$2^{\circ}$ Juzgado de Letras de Talagante, rol 896-2013, González con Cooperativa de Ahorro y Crédito, sentencia de 20/12/2013.

$3^{\circ}$ Juzgado de Letras de Arica, rol 1527-2013, Peña con Escuela Especial de Lenguaje, sentencia de 20/12/2013.

$7^{\circ}$ Juzgado de Letras de Santiago, rol 29374-2012, Pascual con Banco del Estado, sentencia de $13 / 01 / 2014$

$23^{\circ}$ Santiago, rol 4968-2013, Carmona con Capitán de Carabineros, sentencia de 30/01/2014.

$2^{\circ}$ Juzgado de Letras de Antofagasta, rol 5882-2013, Silva con Colegio Chañares, sentencia de $11 / 03 / 2014$.

Juzgado de Letras de Constitución, rol 41-2013, Fuentes con Discoteque Costa Barúa, sentencia de 23/04/2014.

$1^{\circ}$ Juzgado de Letras de ViÑa del Mar, rol 808-2013, Retamal con Terminal de Buses Viña del Mar, sentencia de 29/04/2014. 
$25^{\circ}$ Juzgado de Letras de Santiago, rol 7880-2013, López con INE, sentencia de 06/05/2014. $1^{\circ}$ Juzgado de Letras de Antofagasta, rol 6332-2013, Peña con Tamayo, sentencia de 08/08/2014. Juzgado de Letras de Villarrica, rol 671-2012, Riquelme con Compañía de Bomberos, sentencia de 26/05/2014

$1^{\circ}$ Juzgado de Letras de La Serena, rol 4435-2013, Rojas con Instituto Profesional Providencia, sentencia de 09/06/2014.

$1^{\circ}$ Juzgado de Letras de Concepción, rol 8228-2013, Torres con Colegio Santísima Trinidad, sentencia de 29/06/2014.

$4^{\circ}$ Juzgado de Letras de Antofagasta, rol 5451-2013, Majmud con Seremi OOPP, sentencia de 30/06/2014.

$1^{\circ}$ Juzgado de Letras de Chillán, rol 1901-2014, Riesco con Servicio de Salud Ñuble, 01/08/2014.

$1^{\circ}$ Juzgado de Letras de Valparaíso, rol 3081-2013, Valdebenito con Armada, sentencia de $07 / 08 / 2014$

$2^{\circ}$ Juzgado de Letras de San Miguel, rol 5560-2014, Suárez con Compañia de Bomberos, sentencia de 26/08/2014.

Juzgado de Letras de Río Bueno, rol 52-2014, Obando con Comercial Socoepa S. A., sentencia de $15 / 09 / 2014$.

Juzgado de Letras de San Fernando, rol 514-2013, Carvajal con Duarte, sentencia de $16 / 09 / 2014$.

Juzgado de Letras de Panguipulli, rol 79-2014, Castillo con Escuela Manuel Anabalón Sáez, sentencia de 13/10/2014.

$3^{\circ}$ Juzgado de Letras de Temuco, rol 1279-2014, Fuentealba con Aqueveque, 18/10/2014.

$1^{\circ}$ Juzgado de Letras de Temuco, rol 6545-2013, Leal con Lan, sentencia de 06/11/2014.

$3^{\circ}$ Juzgado de Letras de La Serena, rol 479-2014, Ojeda con SERCOTEC, 13/11/2014.

$2^{\circ}$ Juzgado de Letras de La Serena, rol 1303-2014, Ojeda con SERCOTEC, 24/11/2014.

$3^{\circ}$ Juzgado de Letras de Temuco, rol 3262-2014, García con INDAP, sentencia de 26/11/2014.

$2^{\circ}$ JuZgado de Letras de Valparaíso, rol 1352-2014, Díaz con Armada, sentencia de 02/12/2014.

26 Juzgado de Letras de Santiago; rol 7698-2014, Pavlovic y otros con JUNJI, 16/12/2014.

$7^{\circ}$ Juzgado de Letras de Santiago, rol 10794-2014, Pérez con INDAP, sentencia de 09/02/2014.

$2^{\circ}$ Juzgado de Letras de Temuco, rol 3267-2014, Cid con INDAP, sentencia de 16/02/2015.

2 Juzgado de Letras de SANTiago, rol 10796-2013, Verbal con SERVEL, sentencia de 27/02/2015.

JuZGado De Letras De IllaPel, rol 213-2014, Espinoza con Dijon, sentencia de 9 de marzo de 2015.

$4^{\circ}$ Juzgado de Letras de Santiago, rol 10146-2014, Munnier con SENDA, sentencia de 30 de marzo de 2015.

$2^{\circ}$ Juzgado de Letras de Quillota, rol 2002-2014, Día con Colegio Nuestra Señora del Huerto, sentencia de 24 de abril de 2015.

$2^{\circ}$ Juzgado de Letras de San Bernardo, rol 1975-2014, López con Su Bus S. A., sentencia de 27 de abril de 2015.

Juzgado de Letras de Lautaro, rol 517-2014, Antinao con Van Lankeren y otros, sentencia de 25 de mayo de 2015. 
